RESEÑA DE LIBRo:

\title{
Reseña del libro: Complejos bioculturales de Sonora. Pueblos y territorios indígenas ${ }^{1}$
}

\author{
Maren Von der Borch*
}

Queremos seguir siendo lo que somos, pero no queremos estar como estamos. DON ERASMO LEYVA

Actualmente, un puñado de jóvenes europeos está acaparando el interés de los medios y del mundo académico y político de varios países de Europa y otros continentes. Alejados de las posiciones tanto de la izquierda como de la derecha tradicional, han estado cuestionando los fundamentos mismos del pensamiento económico y social vigente. El economista francés Thomas Piketty, por ejemplo, se ha lanzado contra los mecanismos de redistribución actualmente en uso -como los sistemas de impuestos y los programas sociales- sosteniendo que no hacen más que profundizar las desigualdades sociales. ${ }^{2}$

El activista y escritor inglés George Monbiot, a su vez, sostiene que mientras la apropiación y explotación privada de las riquezas naturales esté limitada solo por el monto de dinero que uno puede poseer, estará en riesgo no solo el presente, sino también el futuro de las siguientes generaciones. A su vez, la adolescente sueca Greta Thunberg y los miles de jóvenes que la están siguiendo, acusan a nuestra generación de estarles robando el futuro debido a nuestra desidia y el afán de acumular riquezas, agotando los recursos no renovables de la naturaleza e ignorando deliberadamente la amenaza del cambio climático.

¿Por qué estoy mencionando esto? Por una razón muy sencilla: revisando las ideas aquí reseñadas, salta a la vista que en su esencia-claro está, sin los fundamentos teóricos y elaboraciones posteriores que les han dado los jóvenes europeos-son el centro mismo del pensamiento ancestral indígena todavía vigente hoy en día en las comunidades, sobre los ciclos de la vida y la naturaleza. "Dios nos ha dado el río a todos, no un pedazo a cada quien", dicen los yaquis de Sonora. Comunidad yoreme (mayo)

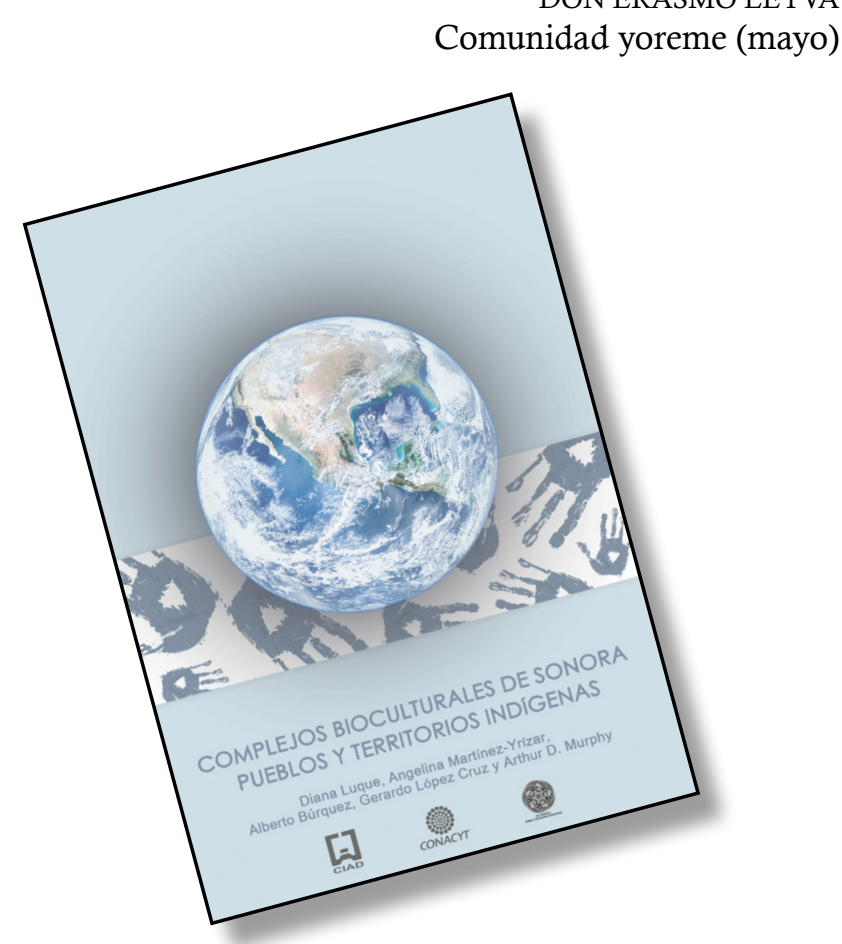

* Socióloga, MTC del Departamento de Trabajo Social de la Universidad de Sonora, marenv@sociales.uson.my

${ }^{1}$ Luque, Diana, Angelina Martínez-Yrizar, Alberto Búrquez, Gerardo López Cruz y Arthur D. Murphy. (2016). Complejos bioculturales de Sonora. Pueblos y territorios indígenas (496 pp.). Cd. de México: CIAD y Red Temática Conacyt sobre Patrimonio Biocultural de México. Colección Patrimonio Biocultural de México. Recuperado de https://www.researchqate, net/profile/Diana Luque2/publication/311921880 Compleos Bioculturales De Sonora Pueblos y Territorios Indigenas/links/58910a03458515aeac92d08f/Complejos-Bioculturales-De-Sonora-Pueblos-y-Territorios-Indigenas.pdi

2 Piketty, Thomas. (2015). La economía de las desigualdades. México: Siglo XXI. 

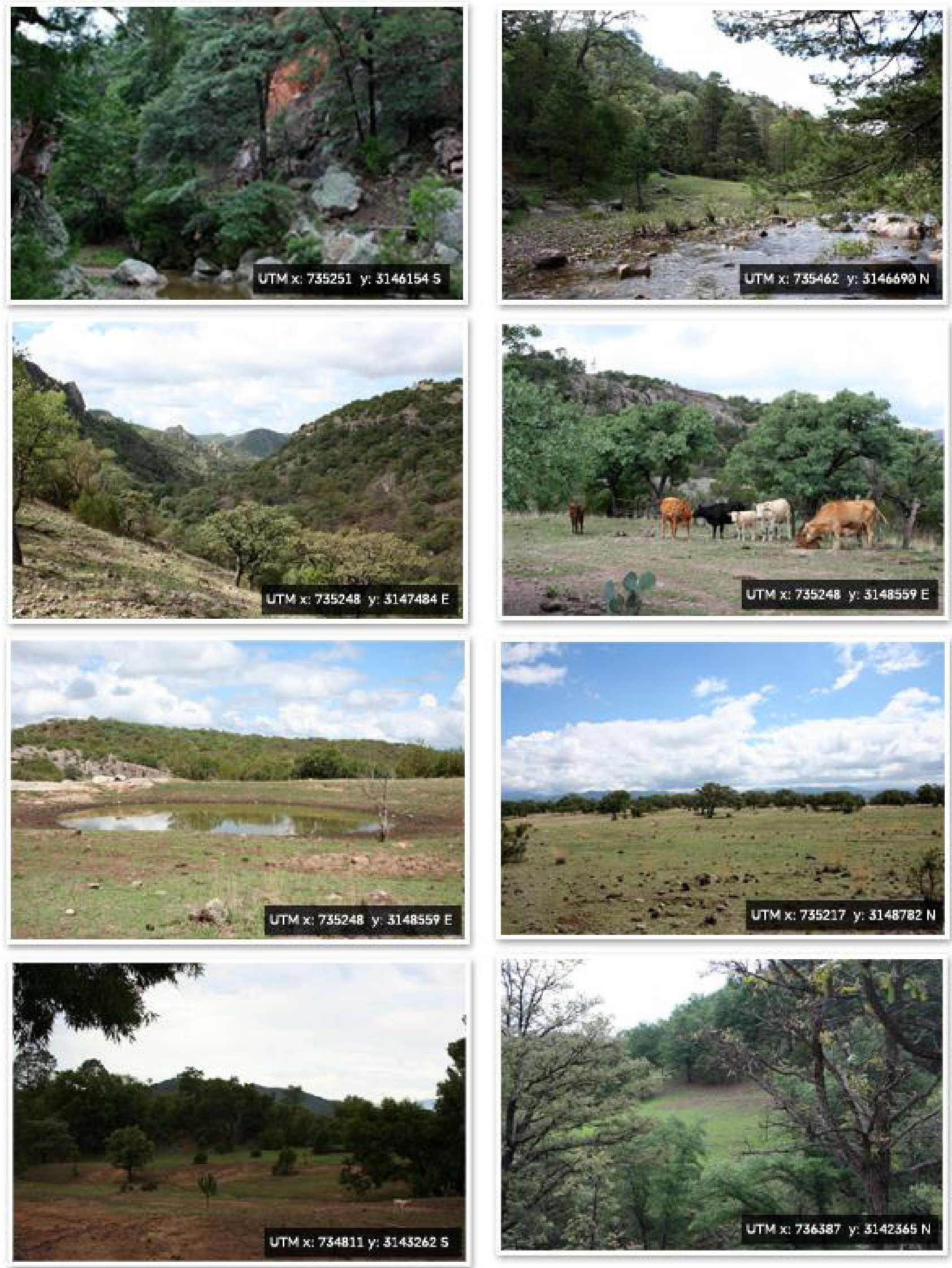

Figura 1. Condiciones ambientales del territorio agrario de la comunidad o'ob (pima) compuesto por un paisaje de sierras, cañadas y cañones, y muy buen estado de conservación de los recursos naturales.

Fuente: fotos tomadas de la versión electrónica del libro deLuque, D., et al. (2016, p. 501). 
La idea misma de la apropiación privada de las riquezas que la naturaleza da, les es ajena a las tradiciones de los pueblos originarios. Aún más la idea de agotar estos bienes -en especial, los no renovables-en busca de la acumulación privada y sin preocuparse por el futuro del conjunto de la comunidad, está en contradicción con el ideal de bienestar o buen vivir de los indígenas sonorenses, por ejemplo, que según Diana Luque y colaboradores gira en torno del "estar en paz, vivir en el territorio, conservar las tradiciones y la lengua materna, vivir en comunidad y por supuesto, comer bien" (p. 343).

Igualmente, muchos de los mecanismos tradicionales de redistribución son muy eficaces -como por ejemplo, el de nombrar mayordomo para un ciclo de fiestas, al que tiene el mayor número de cabezas de ganado. Es un honor ser mayordomo y hacerse cargo de la comida y bebida de toda la comunidad; y al final de las fiestas, el que tenía más animales tiene menos, y no hay nadie en la comunidad que no haya comido y bebido a sus anchas.

Me pareció importante mencionar esto, ya que a mi ver, en ello radica el mérito principal del libro: los indígenas aquí no aparecen como problema, como gente atrasa$d a$, necesitada de programas asistencialistas. Por el con- trario, aparecen como pueblos que a pesar de las múltiples formas de despojo que han experimentado a lo largo de los siglos, y a pesar de sus grandes carencias materiales, han sabido sacar fortaleza de sus tradiciones, adaptándolas continuamente e incorporando saberes y prácticas nuevas. De tal forma, han sabido desarrollar estrategias socioespaciales que les han permitido resistir y conservar su organización comunitaria; cuidar la biodiversidad de sus territorios y preservar la flora y la fauna nativa y los ecosistemas frágiles, como los manglares y los bosques.

Es sabido que en Sonora, como en el resto del país, los niveles más altos de conservación de la naturaleza precisamente se encuentran en zonas indígenas, por lo que los autores afirman: "La presencia de estas comunidades es un factor determinante en la estabilidad y capacidad de resiliencia de dichas regiones" (p. 28). Pero de ninguna manera se puede decir que se trata de un ejercicio de nostalgia:

En ningún momento de la historia, las culturas ni las identidades han sido instituciones estáticas o puras que no cambian ni se mezclan con otras, por lo que enfocarse en los pueblos indígenas como

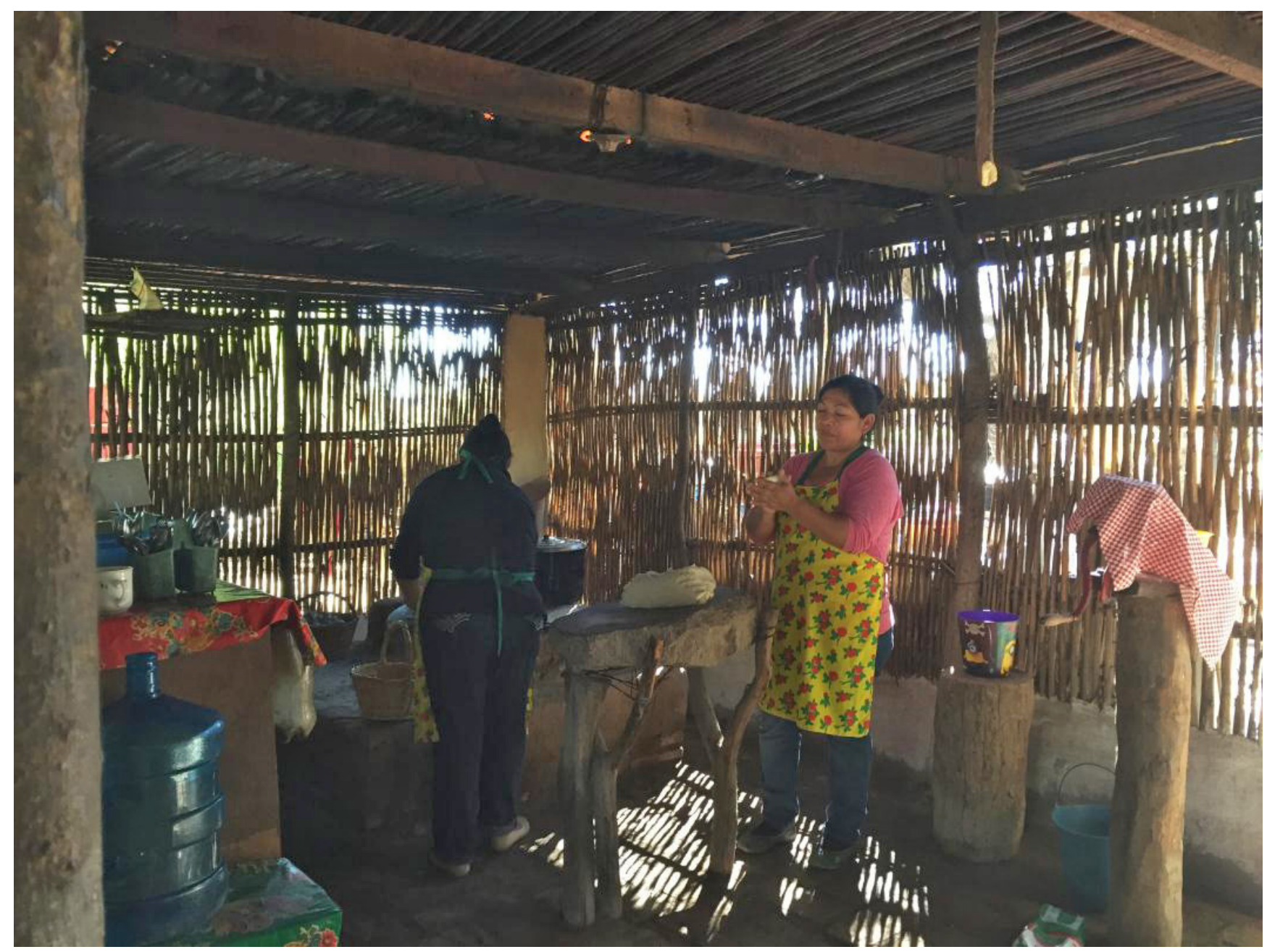

Figura 2. Unidad productiva biocultural (UPB) de gastronomía, ubicada en el Júpare, territorio mayo (yoreme). Fuente: foto tomada de la versión electrónica del libro de Luque, D., et al. (2016, p. 509). 


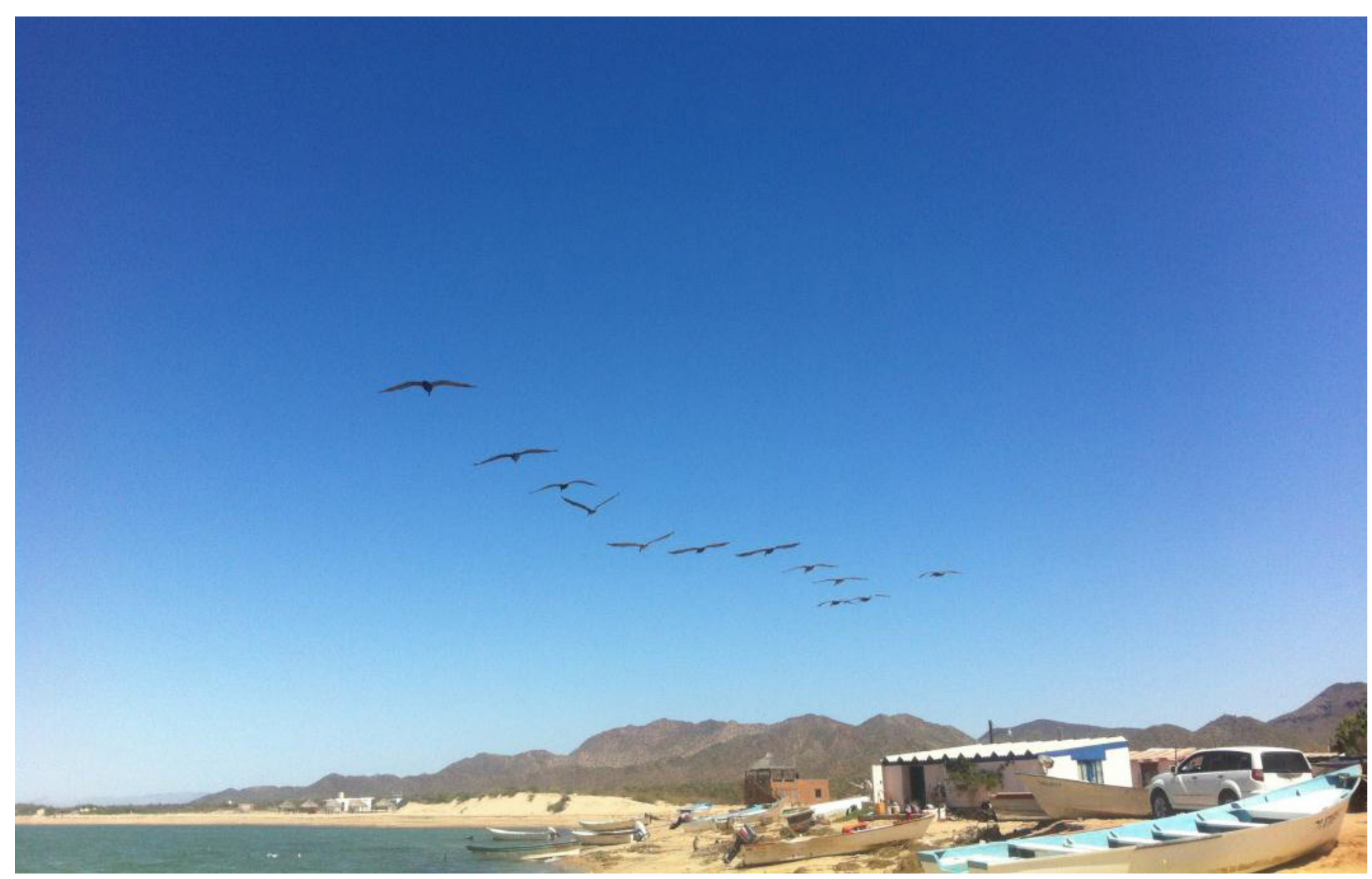

Figura 3. UPB de Pesca en Punta Chueca, Canal del Infiernillo, Territorio comcaac (seri). Al fondo, infraestructura para el ecoturismo.

Fuente: foto tomada de la versión electrónica del libro de Luque, D., et al. (2016, p. 502).

indicadores ambientales o salvadores de la diversidad biológica es negarles su propia historia y su derecho a la libre autodeterminación como pueblos (p. 34).

El objetivo del libro -tal como explican los autoreses:

exponer la crisis ambiental, enfocada en los procesos socioambientales de los pueblos originarios del estado de Sonora: los es-pei (cucapá), tohono o'otham (pápago), comcaac (seri), yoeme (yaqui), yoreme (mayo), mahkurawe (guarijío) y o'ob (pima), los cuales aún se identifican como pueblos, habitan parte de su territorio ancestral y conservan su cosmología ancestral como un eje comunitario identitario (p. 19).

La plataforma analítica de los autores está basada en el pensamiento complejo desarrollado por Edgar Morín, que se opone al pensamiento lineal en el sentido de que reconoce la existencia simultánea de orden y desorden; de contradicciones que no se resuelven en una dicotomía binaria; de dualidades y ambigüedades; de la posibilidad de conocer el todo por análisis de las partes, y las partes por el examen del todo.

El abordaje seleccionado por los autores es la perspectiva biocultural que integra lo que generalmente se ha veni- do estudiando por separado: la diversidad biológica, por un lado, y la diversidad cultural, por el otro. El punto de partida es la observación de que "la diversidad biológica y la diversidad cultural son recíprocas y geográficamente coterráneos" (p. 29).

El modelo de este abordaje, lo encontraron los autores en los principios básicos de la cosmovisión indígena, expresada a través de un sinfín de narraciones en las cuales no se distingue entre cultura y naturaleza; entre el mundo humano y no-humano; entre la tierra y el cielo. Son narraciones que reflejan transmutaciones y reencarnaciones; relatos de animales que se consideran humanos envueltos en ropajes de animales; tortugas marinas que hablan la lengua materna; venados y maíces, osos y bosques, águilas y nopales. Desde ahí, los autores concluyen: "Desde tiempos remotos la trama de la vida se reconoce desde la diversidad, lo que se convierte en una dimensión central de toda la gama de expresiones culturales" (p. 18).

El núcleo central de la argumentación gira en torno de la noción de complejo biocultural: la unidad de comunidad y territorio. Según van explicando los autores, este enfoque -que pertenece a la ecología política- "pretende dar cuenta de la heterogeneidad de los procesos comunitarios marcados estructuralmente por el avance del sistema capitalista, en un contexto de discriminación, desigualdad y marginación sistémica" (p. 41). 
De tal forma, la perspectiva de los complejos bioculturales busca comprender, no solo las transformaciones, adaptaciones y luchas de reivindicación del patrimonio biocultural, sino también de los sistemas productivos y políticos; el manejo del agua, el lenguaje, los sistemas alimentarios, empleo, salud, educación y vivienda; el cumplimiento de los derechos humanos y los derechos de los pueblos indígenas, las relaciones de género e intergeneracionales. Visto así, la perspectiva de los complejos bioculturales puede ser considerada como "un verdadero constructo político de resistencia" (p. 42).

Para poder cubrir este amplísimo espectro de problemáticas, se formó un equipo interdisciplinario, intercultural e intergeneracional en el que aparte de los cinco coordinadores -antropólogos, ecólogos y lingüistas- participaron líderes de las comunidades, así como jóvenes habitantes de estas comunidades y jóvenes académicos, como equipo de apoyo técnico.

La estrategia de investigación ha sido una combinación de actividades que ha permitido corroborar continuamente la información obtenida:

1. Una serie de entrevistas estructuradas a autoridades tradicionales
2. Una serie de entrevistas semiestructuradas a autoridades tradicionales, funcionarios públicos y actores sociales clave

3. Una encuesta sobre subsistencia y biodiversidad

4. Observación participativa y

5. La revisión de documentos hemerográficos y oficiales, reportes técnicos y bibliografía pertinente (p. 370).

De un valor extraordinario es el abundante material gráfico que acompaña a los capítulos: cuadros, gráficas, tablas y mapas muy detallados sobre población, tipos de vegetación, usos del suelo, concesiones mineras, etcétera.

El resultado es un libro de referencia imperdible para interesados en las comunidades indígenas de Sonora, en cuestiones de desarrollo social y de paso también -y he ahí otra vez la conexión con los jóvenes europeos citados al inicio- en el futuro de nuestro planeta: "La pertinencia del 'discurso biocultural' radica en que está mostrando capacidad de regeneración de la comunidad humana frente a sus dilemas contemporáneas" (p. 45).

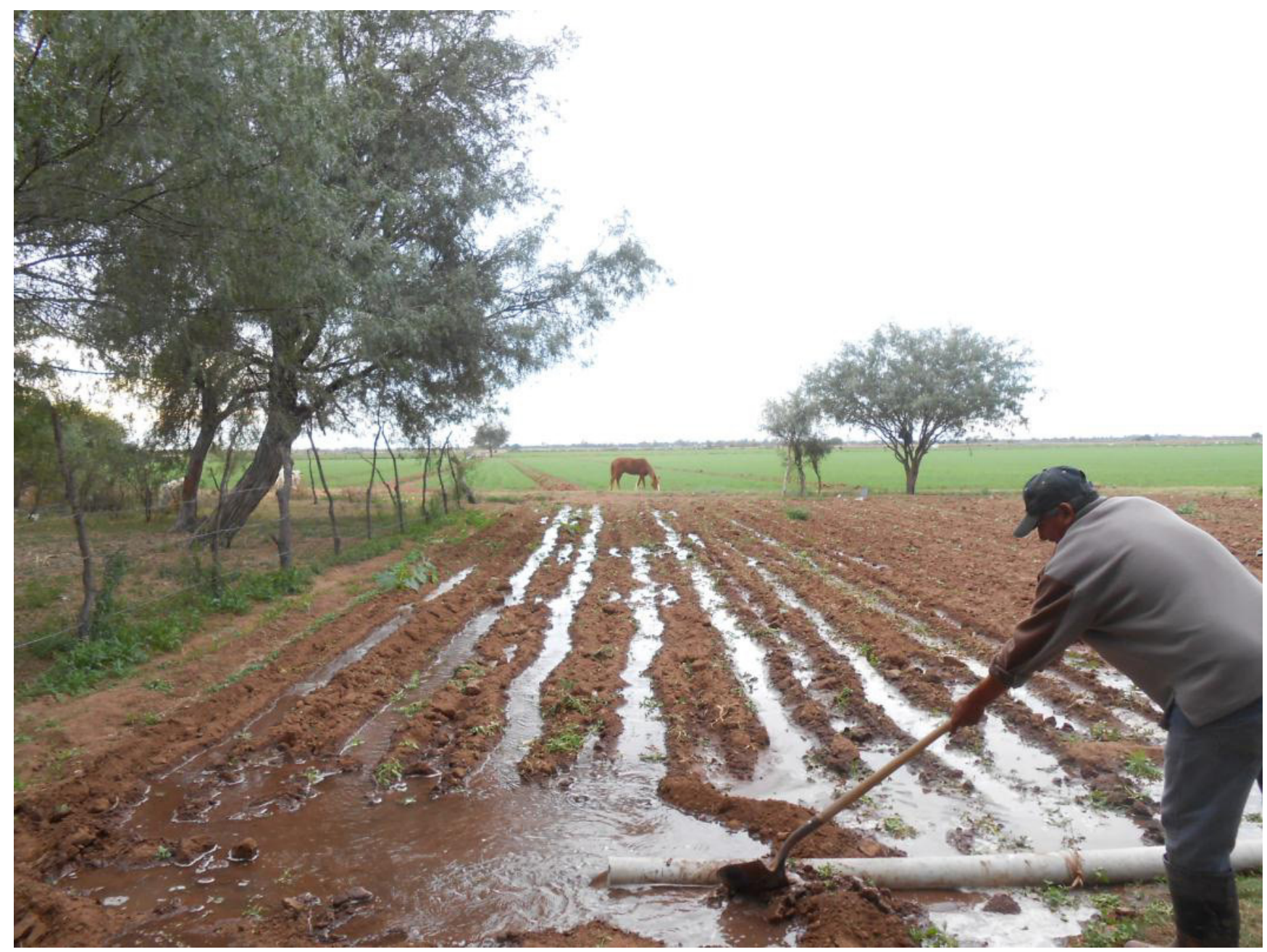

Figura 4. UPB sembradío de traspatio, a un lado de parcelas del distrito de riego, San Antonio, territorio mayo (yoreme)

Fuente: foto tomada de la versión electrónica del libro de Luque, D., et al. (2016, p. 508). 